\title{
Enhanced biomaterials: systematic review of alternatives to supplement spine fusion including silicon nitride, bioactive glass, amino peptide bone graft, and tantalum
}

\author{
Brian Fiani, DO, ${ }^{1}$ Ryan Jarrah, BS, ${ }^{2}$ Jennifer Shields, BS, ${ }^{3}$ and Manraj Sekhon, BS ${ }^{4}$ \\ ${ }^{1}$ Department of Neurosurgery, Desert Regional Medical Center, Palm Springs, California; ${ }^{2}$ College of Arts and Sciences, \\ University of Michigan-Flint; ${ }^{3}$ College of Human Medicine, Michigan State University, East Lansing; and ${ }^{4}$ William Beaumont \\ School of Medicine, Oakland University, Rochester, Michigan
}

\begin{abstract}
OBJECTIVE Spinal fusions are among the most common and effective spinal surgical practices; however, the current model presents some cost and safety concerns within the patient population. Therefore, enhanced biomaterials have been presented to be an innovative yet underutilized tool to supplement the success of spinal fusion surgery. Herein, the authors discuss these biomaterials, their compositions, clinical outcomes, and cost analysis through a systematic review of the literature to date.

METHODS This systematic review was conducted using the PRISMA (Preferred Reporting Items for Systematic Reviews and Meta-Analyses) criteria and guidelines. Article selection was performed using the PubMed electronic bibliographic databases. The search yielded 1168 articles that were assessed and filtered for relevance by the four authors. Following the screening of titles and abstracts, 62 articles were deemed significant enough for final selection.

RESULTS To date, silicon nitride, bioactive glass, amino peptide bone grafts, and tantalum are all biomaterials that could have significant roles in supporting spinal fusion. Their unique compositions allow them to be biocompatible in the spine, and their mechanisms of action stimulate osteoblast formation and support fusion success. Moreover, these biomaterials also present positive clinical and cost outcomes that support their application in spinal procedures. However, further studies with longer follow-ups are necessary to fully understand these biomaterials prior to their incorporation in mainstream spinal practice.
\end{abstract}

CONCLUSIONS The combination of their positive clinical outcomes, biocompatibility, and cost-effectiveness makes these biomaterials valuable, innovative, and effective treatment modalities that could revolutionize the current model of spinal fusion.

https://thejns.org/doi/abs/10.3171/2021.3.FOCUS201044

KEYWORDS biomaterials; bone graft; fusion; amino peptide; allograft; silicon nitride; bioactive glass; tantalum

$\mathrm{D}$ EGENERATIVE and painful spinal pathologies have led to a devastating and disabling patient experience in much of the global population. Whereas analgesics, chiropractic care, physical therapy, epidural steroid injections, and spinal decompressions have all offered relative success, they rarely lead to a natural and complete recovery. ${ }^{1}$ Therefore, spinal fusion surgery has often presented itself as a valuable procedure in the correction of these conditions. ${ }^{1}$ The current model for spinal fusion surgery involves the use of rods, cages, and plates complemented with autologous bone grafts to induce bone growth and achieve optimal fusion success. ${ }^{2}$ However, much of this instrumentation has led to cost and safety concerns among patients, while also prolonging and complicating the recovery process. ${ }^{2}$ Moreover, due to the greater prevalence of aging populations reducing the possibility of using autologous bone grafts, newer and more sophisticated techniques are warranted in order to aid in

ABBREVIATIONS ABM = anorganic bone matrix; $A C D F=$ anterior cervical discectomy and fusion; $A L I F=$ anterior lumbar interbody fusion; BMP = bone morphogenetic protein; P-15 = 15-amino-acid polypeptide residue; PEEK = polyetheretherketone; PLIF = posterior lumbar interbody fusion; TLIF = transforaminal lumbar interbody fusion; VAS = visual analog scale.

SUBMITTED December 6, 2020. ACCEPTED March 22, 2021.

INCLUDE WHEN CITING DOI: 10.3171/2021.3.FOCUS201044. 
spinal fusion success. ${ }^{2}$ With improved understanding of the molecular mechanisms that drive osteoblast formation, biomaterials have emerged as an alternative modality that stimulates the physiological response of the body to induce spinal fusion. ${ }^{1}$

The expansion and application of biomaterials in clinical practice is a novel and multidisciplinary tool in the management of various pathologies. Their incorporation has been well discussed in plastic surgery, dentistry, and dermatology, but they have also been instrumental in spinal surgical practice. ${ }^{3-5}$ Generally, biomaterials are of two types: those from a biological source (collagen, elastin) or those from an artificial source (ceramics, composites, polymers). ${ }^{6}$ Nevertheless, their function is the same, in that supplemental biomaterials are instructed to allow for the presentation of specific growth factors by activating the mechanisms that drive them. ${ }^{1}$ In their application in the spine, they induce growth factor activation to accelerate bone growth and development. ${ }^{2}$ Currently, silicon nitride, bioactive glass, amino peptide bone grafts, and tantalum are among the biomaterials that have been used as newer alternatives to support spinal fusion. Although they are not implemented completely into widespread clinical care, they have shown favorable clinical and in vivo outcomes that highlight them as potential substitutes for the current models of spinal fusion. Herein, this systematic review will address the composition, molecular mechanisms, clinical efficacy, and outcomes, as well as the cost-effectiveness of these materials. The objective of this review is to enlighten spine surgeons and researchers about the functional, clinical, and financial benefits of these biomaterials, along with the biological properties that support spinal fusion. Moreover, we aim to provide a comprehensive and up-todate overview of biomaterials as an uncommon yet effective alternative to the current model of spinal fusion.

\section{Methods}

This systematic review was conducted using the PRISMA (Preferred Reporting Items for Systematic Reviews and Meta-Analyses) criteria and guidelines. Article selection was performed using the PubMed electronic bibliographic databases. The following keywords were used in the search: "biomaterials," "bioactive glass," "silicon nitride," "amino peptide bone graft," "tantalum," "spinal fusion," and "spinal fusion properties." No date or study restrictions were imposed, with articles through the year 2020 being accessed, all of which were in the English language. The search yielded 1168 articles that were assessed and filtered for relevance by the four authors. Following the screening of titles and abstracts, 62 articles were deemed significant enough for final selection. The selection was made by using retrospective studies that assess the impact of biomaterials in supporting spinal fusion, case reports, studies with descriptions of how cost-effective these biomaterials are, studies describing the clinical and functional outcomes in patients in whom these biomaterials are used, studies that describe the composition of these biomaterials, and literature that describes the properties of spinal fusion success. No assumptions or simplifications were made when analyzing the literature.

\section{Results}

From the 1168 references, only 62 met the inclusion criteria. The majority of the selected references reported on the functional, clinical, and financial outcomes of silicon nitride, bioactive glass, amino peptide bone graft, and tantalum. With the selected references all highlighting discussions and clinical outcomes, no biases were demonstrated when analyzing or selecting the literature. Figure 1 presents the breakdown used in selecting studies for this systematic review.

\section{Discussion}

\section{Spinal Fusion Properties}

Spinal fusions are biologically achieved through the activity of osteoblasts and osteoclasts, along with the signaling pathways that support their functions. ${ }^{7}$ Namely, osteoblasts are cells that are responsible for the formation and mineralization of bone. These cells arise from mesenchymal stem cells, yet are not fully differentiated until further signal processing events occur. These processing events occur through the activity of bone morphogenetic proteins (BMPs) and Wnt signaling. On recognition of the immature osteoblasts, two members of the BMP family, BMP2 and BMP4, aid in the phosphorylation of the transcription factor, SMAD1/5/8. In combination, Wnt signaling allows for $\beta$-catenin stabilization and protein kinase $C \delta$ activation. Together, the activation of Wnt signaling products along with phosphorylated SMAD1/5/8 allows for the stimulation of the transcription factor, Runx2. Runx 2 is a key protein in osteoblast stimulation/differentiation and is crucial for bone formation and eventual fusion (Fig. 2). In contrast, the activity of osteoclasts is also integral to spinal fusion, because they allow for the breakdown and removal of old bone to allow for bone remodeling. Osteoclasts are differentiated by hematopoietic cells and are subsequently matured by using the RANKL produced on osteoblasts. This RANKL will bind to the RANK receptor on immature osteoclasts to trigger osteoclast differentiation. However, despite its importance in bone remodeling, overexpression of osteoclasts has proven to inhibit bone formation and potential spinal fusion.

By understanding the intracellular mechanisms that are involved in spinal fusion, surgeons can potentially enhance fusion success by evaluating the roles of supplemental biomaterials. Current epidemiological data suggest that the prevalence of spinal degenerative diseases is increasing within aging societies. ${ }^{7}$ This means that there are more instances of osteoporosis and low bone quality in patients, indicating unregulated osteoclastogenesis. Consequences include lower osteogenic quality of autologous bone grafts, increased risk of instrumentation failure, and eventual fusion failure. However, by incorporating supplemental biomaterials into surgical practice, one can promote the intracellular upregulation of osteoblastic activators through intracellular homeostatic mechanisms. These biomaterials can then enhance the osteogenic quality and structural integrity of the vertebrae by promoting bone formation that allows for successful bone grafting, vertebral scaffolding, and eventual fusion success. 


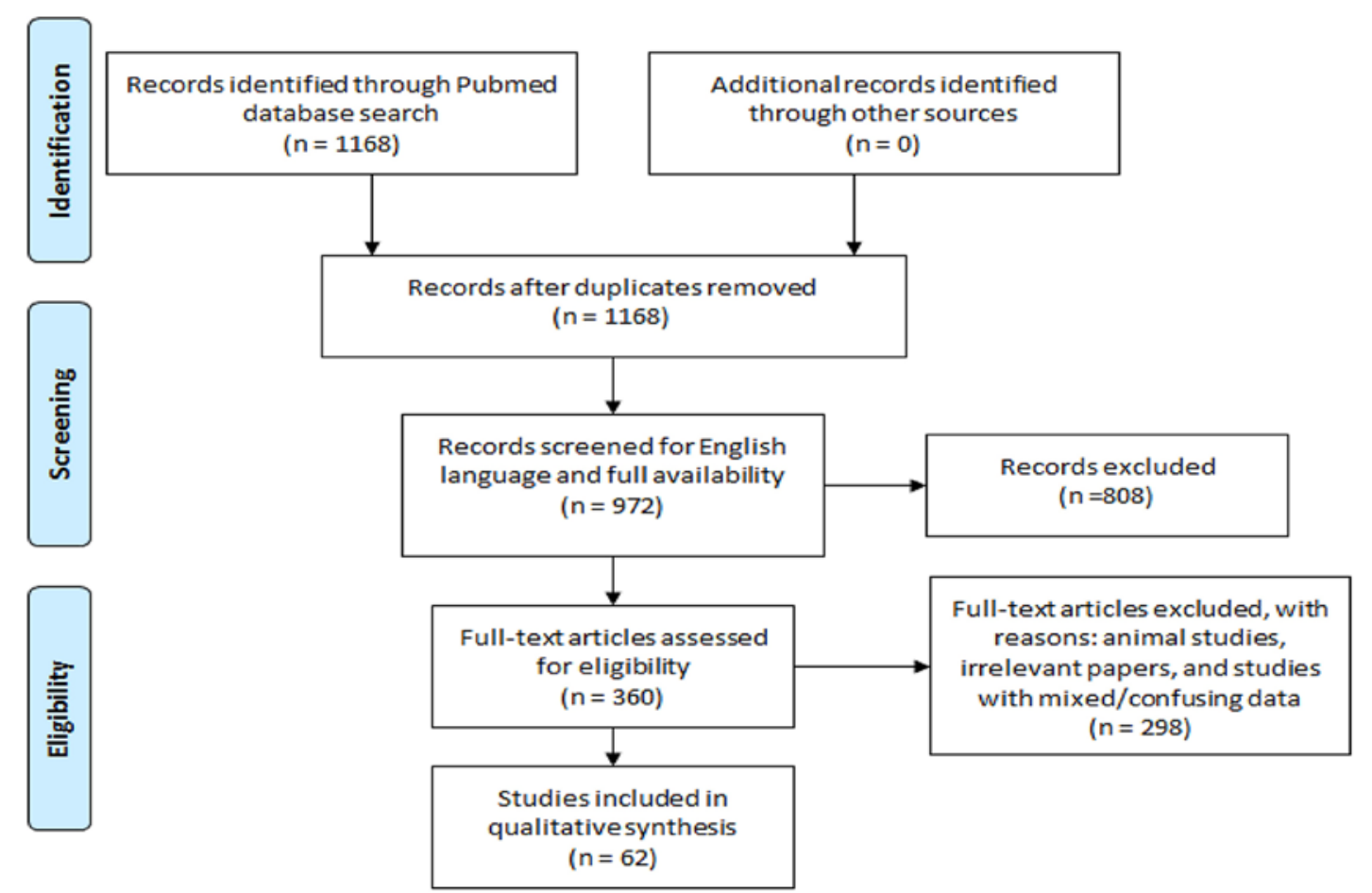

FIG. 1. PRISMA guidelines flowchart for references.

\section{Silicon Nitride}

Silicon nitride $\left(\mathrm{Si}_{3} \mathrm{~N}_{4}\right)$ is an inorganic, nonmetallic, nonoxide ceramic with unique material phase stability. With an array of favorable properties, including low-density hardness, high heat and thermal shock resistance, high corrosion and abrasion resistance, good mechanical and flexural strength, and high fracture toughness, it has been an attractive option for many structural, high-performance applications. ${ }^{8,9}$ Whereas it has been primarily used for industrial purposes since its initial development, it has more recently been considered in biomedical roles. Because its properties are biocompatible, bio-inert, and stable in vivo, silicon nitride has been used in interbody spinal fusion cages, components of hip and knee prostheses, and maxillofacial reconstruction, with research underway for use as implants in dental restoration. ${ }^{8,10}$ Among the more than 35,000 spinal fusions performed using silicon nitride implants through 2018 , less than $0.07 \%$ manifested adverse events reportable to the FDA. ${ }^{11}$

The surface topography and chemistry of silicon nitride are highly modifiable. Whereas the surface structure may be engineered to range from highly fibrous to ultrasmooth, this allows for medical-grade implants to be manufactured in such a way that they can simulate the inherent characteristics of living cortical-cancellous bone with a structure that is dense, porous, or a mixture of the two. ${ }^{8,12,13}$ Similarly, the surface chemistry can be altered from that of silica-rich to principally silicon-amine; this variation in composition influences the in vivo response of cellular components, fluids, tissues, and possible pathogens. ${ }^{8}$ Due to lattice defects along the compound's surface, it behaves as a zwitterion, in which there is a mingling of positive and negative charges. ${ }^{14}$ This establishes a hydrophilic interface as well as a variable negative surface charge at homeostatic $\mathrm{pH}$ that imparts many desirable features, including better protein adsorption (e.g., laminin, fibronectin, vitronectin), enhanced bone affinity, increased osseointegration, and more osteoconductivity than that of other implant biomaterials. ${ }^{9}{ }^{12,14-16}$ Furthermore, the surface structure, chemical composition, and hydrophilicity contribute to the biomaterial's inherent resistance to bacterial adhesion and colonization. ${ }^{12,15-18}$ Moreover, with a low wear rate, the tribochemical dissolution of silicon nitride from the implant surface produces minimal wear particles that are soluble and resorb in biological fluids, minimizing particle load and aseptic loosening, thereby improving the long-term clinical performance of the device., ${ }^{9,19,20}$ Overall, silicon nitride has exhibited no cytotoxic effects, and the extent of immune activation and inflammatory response is trivial. $9,15,16,21$

Not only are silicon nitride implants compatible with all imaging modalities, but they also provide superior image quality. The composition of silicon nitride provides a semiradiolucent nature to the implants, with distinctly visible boundaries that do not obscure the perception and clarity of underlying bone. ${ }^{8}$ Additionally, these implants possess dielectric and nonmagnetic properties, resulting in no distortion, artifact, or scattering on CT and MRI sequences. $^{22,23}$ These advantageous features allow intraoperative assessment for precise placement, as well as simple postoperative evaluation and monitoring.

Application of silicon nitride in the biomedical domain is limited, in part due to practical barriers such as the material's expense and costs associated with conventional 


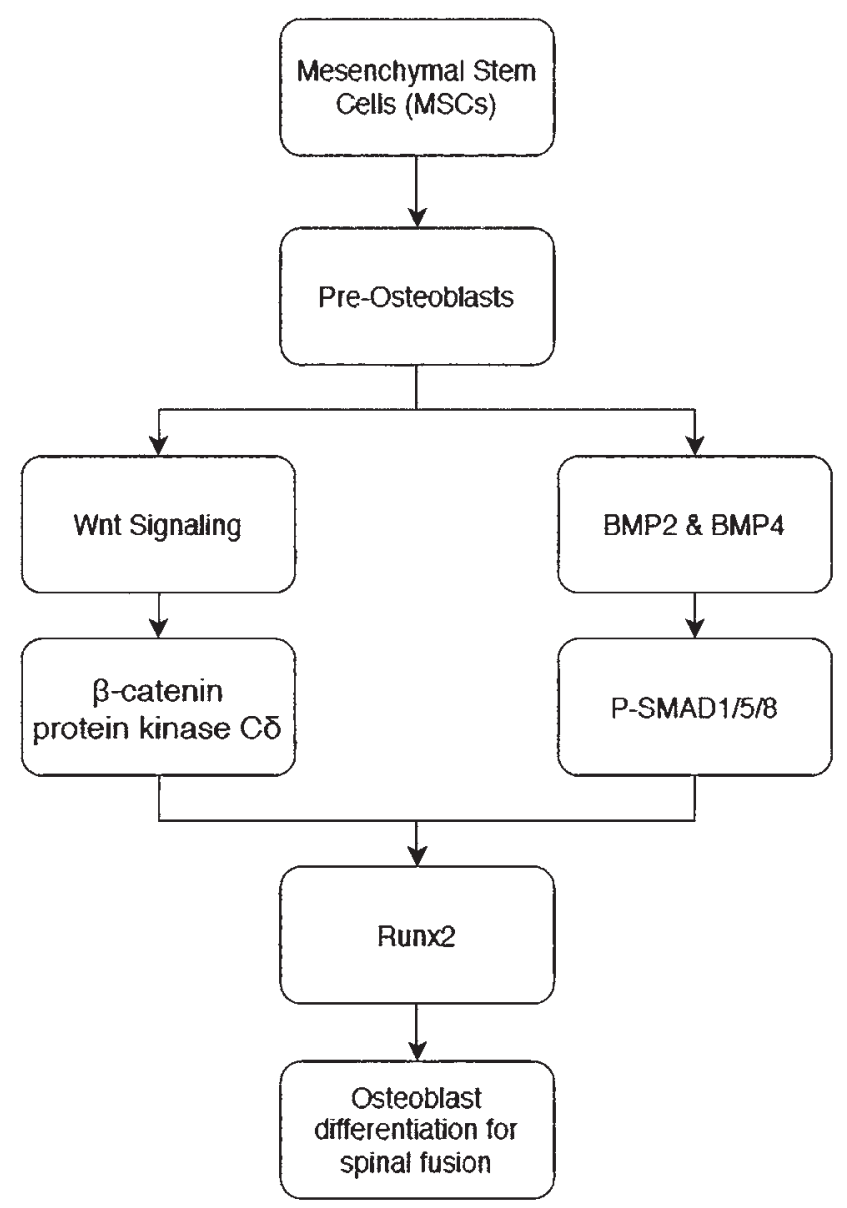

FIG. 2. The cellular mechanism for osteoblast differentiation. Preosteoblasts are synthesized from mesenchymal stem cells and will undergo signal processing events from Wnt signaling and BMPs to stimulate Runx2. Activated Runx2 allows for the osteoblast differentiation that is necessary for spinal fusion.

processing methods, especially considering the compound's characteristically high degree of hardness. ${ }^{8,10,24}$ Costs for production are relatively comparable to those of polyetheretherketone (PEEK) manufacturing. However, manufacturers may find further efficiency with robocasting (a form of 3D printing) of silicon nitride implants, leading to decreased production expenses and improved cost-effectiveness and clinical availability. ${ }^{8,24}$ Yet, notably, the ratio of performance to cost benefit is superior to that of other biomaterials and will surely support the further advancement and incorporation of silicon nitride across many medical disciplines.

\section{Bioactive Glass}

Bioactive glass is another enhanced and innovative biomaterial that has an abundance of clinical value, particularly in spinal fusion and bone regeneration. Bioactive glass is an inorganic, semicrystalline, sol-gel material that can react with bodily fluids to induce antimicrobial, osteoblast-stimulating, and tissue-regenerating activity. When it is introduced into the body, bodily fluids will degrade it, causing the glass network to dissolve and allow for specific ion exchange to occur. ${ }^{25}$ These ions include calcium and phosphorus, which when reacted together will form a layer of hydroxyapatite, the inorganic constituent of bone that is responsible for forming bonds between soft and hard tissue. This layer is used in the spine to enhance protein adsorption, act as a scaffold for vertebral stability, enhance integration with surrounding bone, and ultimately serve for spinal fusion success.

The composition of bioactive glass involves an elegant collaboration of specific compounds that allows for an optimized physiological response. The material is fundamentally 4 main oxides that when crystalized together form a softer, glass-like network. The first bioactive glass, $45 \mathrm{~S} 5$, was composed of molar percentages of $46.1 \%$ silicon dioxide $\left(\mathrm{SiO}_{2}\right), 24.4 \%$ sodium monoxide $(\mathrm{NaO}), 26.9 \%$ calcium monoxide $(\mathrm{CaO})$, and $2.6 \%$ phosphorus pentoxide $\left(\mathrm{PO}_{5}\right)$. However, current variations have experimentally altered these percentage values. ${ }^{26,27}$ Nevertheless, bioactive glass is engineered to have higher $\mathrm{NaO}$ and $\mathrm{CaO}$ concentrations due to the biocompatibility of their cations within the physiological environment. ${ }^{26} \mathrm{~A}$ high ratio of $\mathrm{CaO} / \mathrm{P}_{2} \mathrm{O}_{5}$ is also composed to allow the synthesis of the hydroxyapatite surface layer that is so useful for bone and tissue regeneration. Moreover, since its development more than 50 years ago, new compositions of ions have been incorporated for specific clinical applications. In particular, silver ions have been integrated to allow for antimicrobial effects against bacterial strains of Pseudomonas aeruginosa and Staphylococcus aureus, without compromising the activity of osteoblasts. ${ }^{26}$ Moreover, strontium has also been integrated into certain compositions of bioactive glass in order to treat osteoporosis. Strontium ion delivery into sites of weakened bone has been able to inhibit osteoclastic mechanisms and strengthen the region with the defect. ${ }^{26,27}$

The growing yet limited literature regarding the application of bioactive glass in spinal fusion reveals positive clinical outcomes. Results and methods of some key studies are summarized in Table 1.

Bioactive glass has also been characterized for its cost/ benefit value to patients and surgical distributors. A recent study analyzed the cost-effectiveness in patients with chronic osteomyelitis by comparing patients receiving 1-stage treatment of bioactive glass versus those treated with an alternative technique, gentamicin-loaded polymethylmethacrylate beads. ${ }^{32}$ The results showed that patients treated in the bioactive glass cohort had significantly lower hospital costs while also revealing more effective clinical outcomes. The material was shown to have decreased the cost of treatment by almost $\$ 8000$, while also having an incremental cost-effectiveness ratio estimated at $\$ 63,842 .{ }^{32}$ This means that a patient whose treatment was successful would save an estimated amount of $\$ 63,842$ when taking into account the direct cost savings together with the beneficial combination of positive clinical outcomes. ${ }^{32}$ Bioactive glass has also shown cost-effectiveness in alternative ways simply through its versatile commercial application. The material can be used for bone grafts and polymer composites while also being able to mold into different structural forms such as putties, increasing 
TABLE 1. General overview of the clinical outcomes from various BaG studies

\begin{tabular}{|c|c|c|}
\hline Authors \& Year & Methods & Key Findings \\
\hline \multirow[t]{3}{*}{$\begin{array}{l}\text { Westerlund \& Borden, } \\
2020^{28}\end{array}$} & 248 pts were evaluated w/ a spherical BaG putty & $\begin{array}{l}\text { Across } 248 \text { pts, BaG had a 100\% rate of fusion } \\
\text { success }\end{array}$ \\
\hline & $\begin{array}{l}115 \text { pts had ACDF procedures \& } 133 \text { had lumbar } \\
\text { fusions }\end{array}$ & $\begin{array}{l}\text { Successfully assessed in } 93 \% \text { of pts w/ ACDF \& } \\
89 \% \text { of pts w/ lumbar fusion after final FU }\end{array}$ \\
\hline & $\begin{array}{l}\text { Outcomes were evaluated at } 1 \& 2 \text { yrs using radio- } \\
\text { graphic imaging \& the VAS for pain }\end{array}$ & No adverse effects observed \\
\hline \multirow[t]{2}{*}{ Cottrill et al., $2020^{29}$} & Systematic review \& meta-analysis & $\begin{array}{l}\text { Across } 396 \text { pts treated w/ BaG, fusion was } \\
\text { observed in } 84 \%\end{array}$ \\
\hline & $\begin{array}{l}\text { Search yielded } 396 \text { pts treated w/ BaG across } 12 \\
\text { clinical studies }\end{array}$ & $\begin{array}{l}\text { BaG offers clinical value as an autograft extender } \\
\text { in spinal fusion }\end{array}$ \\
\hline \multirow[t]{2}{*}{$\begin{array}{l}\text { Barrey \& Broussolle, } \\
2019^{30}\end{array}$} & $\begin{array}{l}30 \mathrm{pts} \text { w/ a range of cervical \& lumbar degenerative } \\
\text { \& traumatic conditions underwent lumbar fusion } \\
\text { w/ BaG }\end{array}$ & $30 / 30$ pts achieved spinal fusion w/ BaG \\
\hline & $\begin{array}{l}\text { Evaluated based on VAS score \& postop radiograph- } \\
\text { ic images at } 1 \mathrm{yr}\end{array}$ & $\begin{array}{l}90 \% \text { of pts showed recovery at the } 1-\mathrm{yr} \mathrm{FU}, \mathrm{w} / \\
\text { pain reduction estimated at } 60 \%\end{array}$ \\
\hline \multirow[t]{2}{*}{$\begin{array}{l}\text { Ilharreborde et al., } \\
2008^{31}\end{array}$} & $\begin{array}{l}88 \text { pts underwent spinal fusion for adolescent } \\
\text { idiopathic scoliosis; one group used iliac crest } \\
\text { autograft ( } n=40), \text { \& one group used BaG }(n=48)\end{array}$ & $\begin{array}{l}\text { BaG was observed to be as effective as iliac } \\
\text { crest autograft, the premier material for spinal } \\
\text { fusion }\end{array}$ \\
\hline & $\begin{array}{l}\text { Pts were evaluated after 2-yr FU; history, examina- } \\
\text { tion, \& radiographs were used to evaluate success }\end{array}$ & $\begin{array}{l}\text { BaG cohorts had less prevalence of infection \& } \\
\text { mechanical failure }\end{array}$ \\
\hline
\end{tabular}

$\mathrm{BaG}=$ bioactive glass; $\mathrm{FU}=$ follow-up; pts = patients.

its clinical and commercial value. ${ }^{26}$ Furthermore, the fact that the material is inorganic allows for a limitless supply to be manufactured without needing cadaver or patientsupplied bone donations. This makes the manufacturing process easier in comparison to other bone graft alternatives. These combinations of financial, commercial, and clinical benefits of bioactive glass make it a valuable device in the future of spinal surgery.

\section{Amino Peptide Bone Graft}

A novel amino peptide bone graft composite, i-Factor (Cerapedics, Inc.) consists of a synthetic 15-amino-acid polypeptide residue (P-15) adsorbed onto an anorganic bone matrix (ABM), suspended in an inert hydrogel carrier. ${ }^{33}$ The P-15 peptide acts as a biomimetic, containing sequences found in type I collagen, which enables the peptide to bind osteogenic cells, promoting synthesis of the extracellular matrix and cell growth. Osteoconduction is enhanced in combination with ABM, a calcium phosphate scaffold, where biochemical and mechanical communication pathways result in osteogenesis. ${ }^{34-36}$

In an ovine lumbar interbody fusion model, Sherman et al. compared anterior lumbar interbody fusion (ALIF) at L3/L4 and L4/L5 using PEEK interbody rings containing autogenous bone at one spinal level and ABM/P-15 at the other level. They found better fusion with PEEK rings on clinical CT scans obtained at 3 months; however, further imaging and histological analyses showed no statistical differences at 6 months. ${ }^{37}$ With ABM/P-15 widely used in dentistry, Mobbs et al. published one of the first studies of the use of i-Factor in human spinal fusion. ${ }^{38}$ In ALIF procedures, they found that over a mean 24-month follow- up, radiologically observed fusion rates were $92 \%$ in the cohort and $98 \%, 81 \%$, and $100 \%$ for single-, double-, and triple-level fusions, respectively. The mean postoperative Oswestry Disability Index score was 28.42, significantly lower than the preoperative mean score of 61.02 . On a 10 -point scale, pain significantly lowered from 7.4 preoperatively to 2.65 postoperatively, in addition to a significant increase in patient convenience and compliance from 68.27 preoperatively to 92.99 postoperatively. ${ }^{38}$ Complication rates were similar (10\% vs $9.5 \%)$ to those in a large retrospective study of BMP in ALIF. ${ }^{39}$

The first prospective, controlled, long-term trial compared ABM/P-15 versus autograft for use in posterior lumbar interbody fusion (PLIF) over 2 years. ${ }^{40}$ The investigators found $\mathrm{ABM} / \mathrm{P}-15$ to be significantly superior to autologous bone in facilitating faster formation of bridging bone at 6 months (97.73\% vs 59.09\%) and 12 months $(97.78 \%$ vs $82.22 \%)$. However, at 24 months there were nonsignificant differences in fusion. Interestingly, there was a higher degree of bone formation outside the casing for ABM/P-15 (48\%) than with autograft (14\%), which was assumed to be secondary to migration of material outside the cage without any serious adverse events. In addition, this study contained a small sample size and lacked a control group. Recently, a multicenter FDA single-blinded clinical trial approved of i-Factor for C3-7 single-level anterior cervical discectomy and fusion (ACDF). Between i-Factor and autograft, this 2-year patient follow-up found comparable fusion rates ( $97.3 \%$ vs $94.44 \%$ ), neurological success rates, and Neck Disability Index, visual analog scale (VAS) neck and arm pain, and SF-36 scores. ${ }^{33}$ Limitations of this study, however, include participants meeting specific inclusion and exclusion criteria, a lack of blinding 
to surgeons, and the disclosure that Cerapedics, Inc., provided research funding to conduct the FDA investigational device exemption trial. Additional studies comparing clinical outcomes, fusion, and cost between i-Factor and other bone grafts are needed to promote its use in spine surgery.

\section{Tantalum}

First used in surgical sutures in $1940,{ }^{41}$ tantalum is an inert transitional metal used in a wide range of applications within orthopedics, dentistry, vascular surgery, and spine surgery. ${ }^{42}$ Similar in structure to human cancellous bone, porous tantalum is characterized as an open-cell metal structure with an overall porosity of $80 \%$. Possessing a low modulus of elasticity and a high coefficient of friction, it can maintain stability of implants against bone, while optimizing load transfer and reducing shielding. ${ }^{43-45}$ In addition, the open dodecahedron structure of porous tantalum enables better integration with bone, vascular, and other biological substrates, and porous tantalum has been shown in vitro to stimulate osteoblast progenitor formation over titanium fiber mesh and tissue culture plastic. ${ }^{46,47}$

TABLE 2. General overview of the clinical outcomes from various tantalum studies

\begin{tabular}{|c|c|c|}
\hline Authors \& Year & Methods & Results \\
\hline $\begin{array}{l}\text { Cuzzocrea et al., } \\
2019^{53}\end{array}$ & $\begin{array}{l}\text { Retrospective review of } 40 \text { pts who underwent TLIF w/ PEEK } \\
\text { or interbody metal (i.e., Ti or Ta) }\end{array}$ & $\begin{array}{l}\text { - No significant functional differences btwn the } 2 \text { groups } \\
\text { - Increased osteolysis (50\%) of PEEK cages vs } 10 \% \text { of metal } \\
\text { cage cases } \\
\text { - Found the degree of fusion was complete at } 40 \% \text { for metal } \\
\text { cage cases vs } 15 \% \text { for cases w/ PEEK cages at } 1 \text {-yr FU }\end{array}$ \\
\hline $\begin{array}{l}\text { Jalalpour et al., } \\
2015^{54}\end{array}$ & $\begin{array}{l}\text { RCT in which a Ta interbody spacer in TLIF w/ pedicle screw } \\
\text { fixation was compared to a PLF w/ autograft for pts suffer- } \\
\text { ing from }>1 \text {-yr onset of low-back pain }\end{array}$ & $\begin{array}{l}\text { - Ta TLIF group had more significant improvement in VAS pain, } \\
\text { disability rating index, \& global assessment function scores } \\
\text { btwn the } 2 \text { groups } \\
\text { - The fusion rate was nonsignificantly greater for the Ta TLIF } \\
\text { group at } 87 \% \text {, vs } 80 \% \text { in PLF at } 2 \text { yrs }\end{array}$ \\
\hline Lequin et al., $2014^{55}$ & $\begin{array}{l}\text { Compared Ta stand-alone cages in } 26 \text { pts w/ recurrent disc } \\
\text { herniation who were undergoing PLIFs }\end{array}$ & $\begin{array}{l}\text { - Found improved VAS \& functional scores w/o calculated } \\
\text { significance } \\
\text { - Found subsidence at similar levels to the literature \& disc } \\
\text { height significantly increased in the Ta group, but concluded } \\
\text { that it was not correlated w/ clinical outcomes }\end{array}$ \\
\hline \multirow[t]{2}{*}{ Patel et al., $2020^{42}$} & $\begin{array}{l}\text { Systematic review, comparing } 13 \text { studies that evaluated cervi- } \\
\text { cal treatment fusion rates } \mathrm{w} / \mathrm{Ta}\end{array}$ & $\begin{array}{l}\text { - Ta fusion rates were significantly higher when compared to Ta } \\
\text { ring w/ autograft ( } 89 \% \text { vs } 64.8 \% \text { ) } \\
\text { - Ta stand-alone fusion rates were significantly less than in } \\
\text { those who used autograft w/ anterior plate ( } 89 \% \text { vs } 92 \%), w / \\
\text { a FU ranging from } 1 \text { to } 11 \mathrm{yrs}\end{array}$ \\
\hline & $\begin{array}{l}\text { Authors also reviewed } 4 \text { studies in which lumbar fusion w/ Ta } \\
\text { stand-alone graft was compared vs autografts, w/ a FU } \\
\text { ranging from } 6 \text { mos to } 6.8 \mathrm{yrs}\end{array}$ & $\begin{array}{l}\text { - Results showed autograft fusion at } 80 \% \text {, vs } 93.4 \% \text { for Ta } \\
\text { stand-alone graft }\end{array}$ \\
\hline $\begin{array}{l}\text { Fernández-Fairen } \\
\text { et al., } 2008^{56}\end{array}$ & $\begin{array}{l}61 \text { pts who underwent ACDF were evaluated w/ either inter- } \\
\text { body Ta }(n=28) \text { or iliac bone graft }(n=33) \& \text { analyzed w/ } \\
\text { radiographic images \& pain analysis scores }\end{array}$ & $\begin{array}{l}\text { - Fusion rates were statistically similar btwn the } 2 \text { cohorts } \\
\text { - Radiological \& clinical outcomes were similar w/o significant } \\
\text { difference after } 24 \text { mos }\end{array}$ \\
\hline $\begin{array}{l}\text { Fernández-Fairen } \\
\text { et al., } 2019^{57}\end{array}$ & $\begin{array}{l}\text { Retrospective analysis evaluating pts from the } 2008 \text { study at } \\
11 \text {-year FU }\end{array}$ & $\begin{array}{l}\text { - Showed maintained improvement in functional \& pain scores } \\
\text { over an 11-yr FU after ACDF w/ interbody Ta }\end{array}$ \\
\hline $\begin{array}{l}\text { Mastronardi et al., } \\
2018^{58}\end{array}$ & $\begin{array}{l}\text { Retrospective analysis of } 88 \mathrm{pts} w / 1 \text { - to 2-level DDD treated } \\
\text { w/ Ta cages }\end{array}$ & $\begin{array}{l}\text { - } 95.4 \% \text { of pts reported excellent outcomes w/ subjective \& } \\
\text { objective myelopathy improvement } \\
\text { - Fusion rates were } 68.2 \% \text { at } 6 \text { mos \& } 100 \% \text { at } 1 \mathrm{yr} \\
\text { - Only } 2 \text { cases required a second operation w/ Ta cage removal }\end{array}$ \\
\hline $\begin{array}{l}\text { Papacci et al., } \\
2016^{59}\end{array}$ & $\begin{array}{l}\text { Retrospective series study of } 99 \text { pts who underwent ACDF \& } \\
\text { who were treated w/ porous Ta cages }\end{array}$ & $\begin{array}{l}\text { - Statistically significant improvement of all evaluated pt scores } \\
\text { - No reports of major postop complications }\end{array}$ \\
\hline $\begin{array}{l}\text { Tomé-Bermejo et } \\
\text { al., } 2017^{60}\end{array}$ & $\begin{array}{l}\text { Retrospective observational study evaluating } 41 \text { pts w/ DDD } \\
\text { undergoing ACDF w/ lordotic Ta implants }\end{array}$ & $\begin{array}{l}\text { - Final fusion FU rate was } 96.96 \% \\
\text { - Significantly higher interspace height after implant insertion at } \\
\text { final FU }\end{array}$ \\
\hline $\begin{array}{l}\text { Kasliwal et al., } \\
2013^{61}\end{array}$ & $\begin{array}{l}\text { Prospective randomized study involving } 39 \text { pts: } 11 \text { pts received } \\
\text { control iliac autograft, } 13 \text { received a porous Ta ring device } \\
\text { w/ its center packed w/ cancellous iliac crest autograft (hy- } \\
\text { brid), \& } 15 \text { received porous Ta blocks; pts were evaluated } \\
\text { after } 24 \text { mos }\end{array}$ & $\begin{array}{l}\text { - Fusion rate at } 2 \text { yrs for the Ta device was lower compared to } \\
\text { control ( } 44 \% \text { vs } 100 \%) \\
\text { - Concluded stand-alone porous Ta is not ideal for interbody } \\
\text { fusion }\end{array}$ \\
\hline
\end{tabular}

$\mathrm{DDD}=$ degenerative disc disease; $\mathrm{PLF}=$ posterolateral fusion; $\mathrm{RCT}=$ randomized controlled trial; $\mathrm{Ta}=$ tantalum; $\mathrm{Ti}=$ titanium . 
Within animal models, use of porous tantalum in the lumbar spine of rabbits found equivalent radiographic fusion index scores at 12 months postoperatively between autograft and tantalum groups. ${ }^{48}$ In a porcine ALIF model, the radiographic and histological appearances of the porous tantalum ring were equivalent to those of a carbon fiber cage at 3 months. ${ }^{49}$ Furthermore, a study of porous tantalum in the cervical spine of goats showed $35 \%$ bone ingrowth at 6 weeks, which was twice as much as for PEEK implants. However, no difference in mineral apposition rate was observed at 26 weeks. ${ }^{50}$ Human-porous tantalum integration has been reported in tibia trays, patellar specimens, acetabular shells, and femoral stems, with similar levels of bone ingrowth between these anatomical sites. ${ }^{51}$ One of the first prospective randomized controlled trials studying porous tantalum cervical interbody implants found tantalum to have increased fusion rates $(100 \%)$ in groups with tantalum block and ring compared to the control group (87\%) with only autologous bone. ${ }^{52}$

Several studies have reported significant functional and clinical benefits of tantalum, as shown in Table 2. Nevertheless, whereas tantalum has clinical value for fusion success, it does not provide much value for diagnostic imaging. Tantalum has been proposed for use in radiography-however, its high density of $16.6 \mathrm{~g} / \mathrm{cm}^{3}$ will make radiographic images ambiguous for interpretation, therefore limiting the material's clinical versatility. Moreover, systematic cost analyses for various spine procedures involving tantalum have yet to be completed. However, one study found the cost-effectiveness for treatment of ACDF with tantalum versus autograft with plate to be significantly less, at $\$ 6806$ versus $\$ 10,143$. Additionally, the incremental cost-effectiveness ratio of ACDF between tantalum and autograft was $-\$ 1473$ per patient per year, favoring a tantalum implant as the more cost-effective option. ${ }^{62}$ Altogether, further one-to-one studies are needed to compare other spinal procedures such as transforaminal lumbar interbody fusion (TLIF) and PLIF, as well as to uncover its cost-effectiveness for additional spinal procedures.

\section{Conclusions}

Silicon nitride, bioactive glass, amino peptide bone grafts, and tantalum have all been shown to be effective and valuable modalities in supporting spinal fusion. Their unique compositions allow them to be biocompatible in stimulating osteoblast formation and supporting spinal fusion. However, despite these exciting early clinical and cost outcomes, these biomaterials have not had a major market impact. Much of the reason is that studies incorporating these biomaterials remain limited, thereby warranting further research that could provide better indications regarding the application of these biomaterials. These further studies should include longer follow-up durations to further analyze symptoms and complications, radiographic integrations, and clinical outcomes. Moreover, studies of various spinal pathologies and pain levels would also provide more insight into the effects and limitations of these biomaterials. Nevertheless, silicon nitride, bioactive glass, amino peptide bone grafts, and tantalum all provide encouraging financial, functional, and clinical outcomes.
With further longer-term studies, their application should be considered for the future advancement of the current model of spinal fusion surgery.

\section{References}

1. Bowles RD, Setton LA. Biomaterials for intervertebral disc regeneration and repair. Biomaterials. 2017;129:54-67.

2. Duarte RM, Varanda P, Reis RL, et al. Biomaterials and bioactive agents in spinal fusion. Tissue Eng Part B Rev. 2017:23(6):540-551.

3. Dieckmann C, Renner R, Milkova L, Simon JC. Regenerative medicine in dermatology: biomaterials, tissue engineering, stem cells, gene transfer and beyond. Exp Dermatol. 2010;19(8):697-706.

4. Kim JJ, Evans GR. Applications of biomaterials in plastic surgery. Clin Plast Surg. 2012;39(4):359-376.

5. Qasim SSB, Zafar MS, Niazi FH, et al. Functionally graded biomimetic biomaterials in dentistry: an evidence-based update. J Biomater Sci Polym Ed. 2020;31(9):1144-1162.

6. Devi RS, Kumar AS, Bhuvanes E, Kavya C. Biomaterial and its medical applications. Int J Adv Res Innov Ideas Educ. 2017;3(3):489-498.

7. Makino T, Tsukazaki H, Ukon Y, et al. The biological enhancement of spinal fusion for spinal degenerative disease. Int J Mol Sci. 2018;19(8):E2430.

8. Rahaman M, Xiao W. Silicon nitride bioceramics in healthcare. Int J Appl Ceram Technol. 2018;15(4):861-872.

9. Lal S, Caseley EA, Hall RM, Tipper JL. Biological impact of silicon nitride for orthopaedic applications: role of particle size, surface composition and donor variation. Sci Rep. 2018;8(1):9109.

10. Bal BS, Rahaman MN. Orthopedic applications of silicon nitride ceramics. Acta Biomater. 2012;8(8):2889-2898.

11. Calvert GC, VanBuren Huffmon G III, Rambo WM Jr, et al. Clinical outcomes for lumbar fusion using silicon nitride versus other biomaterials. J Spine Surg. 2020;6(1):33-48.

12. Bock RM, McEntire BJ, Bal BS, et al. Surface modulation of silicon nitride ceramics for orthopaedic applications. Acta Biomater. 2015;26:318-330.

13. Bodišová $\mathrm{K}$, Kašiarová $\mathrm{M}$, Domanická $\mathrm{M}$, et al. Porous silicon nitride ceramics designed for bone substitute applications. Ceram Int. 2013;39(7):8355-8362.

14. Pezzotti G, McEntire BJ, Bock R, et al. Silicon nitride: a synthetic mineral for vertebrate biology. Sci Rep. 2016;6:31717.

15. Hampshire S. Non-oxide ceramics as biomaterials. In: Reference Module in Materials Science and Materials Engineering. Elsevier; 2020.

16. Gorth D, Puckett S, Ercan B, et al. Decreased bacteria activity on $\mathrm{Si}_{3} \mathrm{~N}_{4}$ surfaces compared with PEEK or titanium. Int $J$ Nanomedicine. 2012;7:4829-4840.

17. Webster TJ, Patel AA, Rahaman MN, Bal BS. Anti-infective and osteointegration properties of silicon nitride, poly(ether ether ketone), and titanium implants. Acta Biomater. 2012;8(12):4447-4454.

18. Pezzotti G. Silicon nitride: a bioceramic with a gift. $A C S$ Appl Mater Interfaces. 2019;11(30):26619-26636.

19. Olofsson J, Grehk TM, Berlind T, et al. Evaluation of silicon nitride as a wear resistant and resorbable alternative for total hip joint replacement. Biomatter. 2012;2(2):94-102.

20. Pettersson M, Skjöldebrand C, Filho L, et al. Morphology and dissolution rate of wear debris from silicon nitride coatings. ACS Biomater Sci Eng. 2016;2(6):998-1004.

21. Neumann A, Reske T, Held M, et al. Comparative investigation of the biocompatibility of various silicon nitride ceramic qualities in vitro. J Mater Sci Mater Med. 2004;15(10):11351140.

22. Taylor RM, Bernero JP, Patel AA, et al. Silicon nitride: a new material for spinal implants. J Bone Joint Surg Br. 2010;92-B(suppl I):133. 
23. Anderson M, Bernero J, Brodke D. Medical imaging characteristics of silicon nitride ceramic a new material for spinal arthroplasty implants. Paper presented at: 8th Annual Spine Arthroplasty Society Global Symposium on Motion Preservation Technology; May 6-9, 2008; Miami, FL.

24. Zhao S, Xiao W, Rahaman MN, et al. Robocasting of silicon nitride with controllable shape and architecture for biomedical applications. Int J Appl Ceram Technol. 2017;14(2):117-127.

25. Boyan BD, Cohen DJ, Schwartz Z. Bone tissue grafting and tissue engineering concepts. In: Ducheyne P, ed. Comprehensive Biomaterials II. Vol 7. Elsevier; 2017:298-313.

26. Baino F, Hamzehlou S, Kargozar S. Bioactive glasses: where are we and where are we going? J Funct Biomater. 2018;9(1): E25.

27. Fiume E, Barberi J, Verné E, Baino F. Bioactive glasses: from parent 45S5 composition to scaffold-assisted tissue-healing therapies. J Funct Biomater. 2018;9(1):E24.

28. Westerlund LE, Borden M. Clinical experience with the use of a spherical bioactive glass putty for cervical and lumbar interbody fusion. J Spine Surg. 2020;6(1):49-61.

29. Cottrill E, Pennington Z, Lankipalle N, et al. The effect of bioactive glasses on spinal fusion: a cross-disciplinary systematic review and meta-analysis of the preclinical and clinical data. J Clin Neurosci. 2020;78:34-46.

30. Barrey C, Broussolle T. Clinical and radiographic evaluation of bioactive glass in posterior cervical and lumbar spinal fusion. Eur J Orthop Surg Traumatol. 2019;29(8):1623-1629.

31. Ilharreborde B, Morel E, Fitoussi F, et al. Bioactive glass as a bone substitute for spinal fusion in adolescent idiopathic scoliosis: a comparative study with iliac crest autograft. $J$ Pediatr Orthop. 2008;28(3):347-351.

32. Geurts J, van Vugt T, Thijssen E, Arts JJ. Cost-effectiveness study of one-stage treatment of chronic osteomyelitis with bioactive glass S53P4. Materials (Basel). 2019;12(19):E3209.

33. Arnold PM, Sasso RC, Janssen ME, et al. i-Factor ${ }^{\mathrm{TM}}$ bone graft vs autograft in anterior cervical discectomy and fusion: 2-year follow-up of the randomized single-blinded Food and Drug Administration Investigational Device Exemption study. Neurosurgery. 2018;83(3):377-384.

34. Bhatnagar RS, Qian JJ, Gough CA. The role in cell binding of a beta-bend within the triple helical region in collagen alpha 1 (I) chain: structural and biological evidence for conformational tautomerism on fiber surface. J Biomol Struct Dyn. 1997;14(5):547-560.

35. Bhatnagar RS, Qian JJ, Wedrychowska A, et al. Design of biomimetic habitats for tissue engineering with P-15, a synthetic peptide analogue of collagen. Tissue Eng. 1999;5(1):53-65.

36. Kübler A, Neugebauer J, Oh JH, et al. Growth and proliferation of human osteoblasts on different bone graft substitutes: an in vitro study. Implant Dent. 2004;13(2):171-179.

37. Sherman BP, Lindley EM, Turner AS, et al. Evaluation of $\mathrm{ABM} / \mathrm{P}-15$ versus autogenous bone in an ovine lumbar interbody fusion model. Eur Spine J. 2010;19(12):2156-2163.

38. Mobbs RJ, Maharaj M, Rao PJ. Clinical outcomes and fusion rates following anterior lumbar interbody fusion with bone graft substitute i-FACTOR, an anorganic bone matrix/P-15 composite. J Neurosurg Spine. 2014;21(6):867-876.

39. Williams BJ, Smith JS, Fu KM, et al. Does bone morphogenetic protein increase the incidence of perioperative complications in spinal fusion? A comparison of 55,862 cases of spinal fusion with and without bone morphogenetic protein. Spine (Phila Pa 1976). 2011;36(20):1685-1691.

40. Lauweryns P, Raskin Y. Prospective analysis of a new bone graft in lumbar interbody fusion: results of a 2- year prospective clinical and radiological study. Int J Spine Surg. 2015;9:2.

41. Burke GL. The corrosion of metals in tissues; and an introduction to tantalum. Can Med Assoc J. 1940;43(2):125-128.
42. Patel MS, McCormick JR, Ghasem A, et al. Tantalum: the next biomaterial in spine surgery? J Spine Surg. 2020;6(1):72-86.

43. Bobyn JD, Stackpool GJ, Hacking SA, et al. Characteristics of bone ingrowth and interface mechanics of a new porous tantalum biomaterial. J Bone Joint Surg Br. 1999;81(5):907914.

44. Levine BR, Sporer S, Poggie RA, et al. Experimental and clinical performance of porous tantalum in orthopedic surgery. Biomaterials. 2006;27(27):4671-4681.

45. Cohen R. A porous tantalum trabecular metal: basic science. Am J Orthop. 2002;31(4):216-217.

46. Wang Q, Zhang H, Li Q, et al. Biocompatibility and osteogenic properties of porous tantalum. Exp Ther Med. 2015;9(3):780-786.

47. Sagomonyants KB, Hakim-Zargar M, Jhaveri A, et al. Porous tantalum stimulates the proliferation and osteogenesis of osteoblasts from elderly female patients. J Orthop Res. 2011;29(4):609-616.

48. Lu M, Xu S, Lei ZX, et al. Application of a novel porous tantalum implant in rabbit anterior lumbar spine fusion model: in vitro and in vivo experiments. Chin Med J (Engl). 2019;132(1):51-62.

49. Zou X, Li H, Bünger M, et al. Bone ingrowth characteristics of porous tantalum and carbon fiber interbody devices: an experimental study in pigs. Spine J. 2004;4(1):99-105.

50. Sinclair SK, Konz GJ, Dawson JM, et al. Host bone response to polyetheretherketone versus porous tantalum implants for cervical spinal fusion in a goat model. Spine (Phila Pa 1976). 2012;37(10):E571-E580.

51. Hanzlik JA, Day JS. Bone ingrowth in well-fixed retrieved porous tantalum implants. J Arthroplasty. 2013;28(6):922927.

52. Wigfield C, Robertson J, Gill S, Nelson R. Clinical experience with porous tantalum cervical interbody implants in a prospective randomized controlled trial. Br J Neurosurg. 2003;17(5):418-425.

53. Cuzzocrea F, Ivone A, Jannelli E, et al. PEEK versus metal cages in posterior lumbar interbody fusion: a clinical and radiological comparative study. Musculoskelet Surg. 2019;103(3):237-241.

54. Jalalpour K, Neumann P, Johansson C, Hedlund R. A randomized controlled trial comparing transforaminal lumbar interbody fusion and uninstrumented posterolateral fusion in the degenerative lumbar spine. Global Spine $J$. 2015;5(4):322-328.

55. Lequin MB, Verbaan D, Bouma GJ. Posterior lumbar interbody fusion with stand-alone Trabecular Metal cages for repeatedly recurrent lumbar disc herniation and back pain. $J$ Neurosurg Spine. 2014;20(6):617-622.

56. Fernández-Fairen M, Sala P, Dufoo M Jr, et al. Anterior cervical fusion with tantalum implant: a prospective randomized controlled study. Spine (Phila Pa 1976). 2008;33(5):465-472.

57. Fernández-Fairen M, Alvarado E, Torres A. Eleven-year follow-up of two cohorts of patients comparing standalone porous tantalum cage versus autologous bone graft and plating in anterior cervical fusions. World Neurosurg. 2019;122:e156-e167.

58. Mastronardi L, Roperto R, Cacciotti G, Calvosa F. Anterior cervical fusion with stand-alone trabecular metal cages to treat cervical myelopathy caused by degenerative disk disease. observations in 88 cases with minimum 12-month follow-up. J Neurol Surg A Cent Eur Neurosurg. 2018;79(6):496-501.

59. Papacci F, Rigante L, Fernandez E, et al. Anterior cervical discectomy and interbody fusion with porous tantalum implant. Results in a series with long-term follow-up. J Clin Neurosci. 2016;33:159-162.

60. Tomé-Bermejo F, Morales-Valencia JA, Moreno-Pérez J, et 
al. Degenerative cervical disc disease: long-term changes in sagittal alignment and their clinical implications after cervical interbody fusion cage subsidence: a prospective study with standalone lordotic tantalum cages. Clin Spine Surg. 2017;30(5):E648-E655.

61. Kasliwal MK, Baskin DS, Traynelis VC. Failure of porous tantalum cervical interbody fusion devices: two-year results from a prospective, randomized, multicenter clinical study. $J$ Spinal Disord Tech. 2013;26(5):239-245.

62. Fernández-Fairen M, Murcia A, Torres A, et al. Is anterior cervical fusion with a porous tantalum implant a cost-effective method to treat cervical disc disease with radiculopathy? Spine (Phila Pa 1976). 2012;37(20):1734-1741.

\section{Disclosures}

The authors report no conflict of interest concerning the materials or methods used in this study or the findings specified in this paper.

\section{Author Contributions}

Conception and design: Fiani. Acquisition of data: Fiani. Analysis and interpretation of data: Fiani. Drafting the article: all authors. Critically revising the article: all authors. Reviewed submitted version of manuscript: all authors. Approved the final version of the manuscript on behalf of all authors: Fiani. Statistical analysis: Fiani. Administrative/technical/material support: Fiani. Study supervision: Fiani.

\section{Correspondence}

Brian Fiani: Desert Regional Medical Center, Palm Springs, CA. bfiani@outlook.com. 